\title{
Is Surgical Drain Useful for Lumbar Disc Surgery?
}

\author{
Ho Seok Choi, Sang Gu Lee, Woo Kyung Kim, Seong Son, Tae Seok Jeong \\ Department of Neurosurgery, Gachon University Gil Medical Center, Incheon, Korea
}

\begin{abstract}
Objective: Surgical drains are commonly used after the spine surgeries for minimizing hematoma formation, which can delay wound healing and may become a source of fibrosis, infection, and pain. The drain, however, may provide a direct route for infection if it is contaminated. Our objective was to survey the relationship between surgical drains and infection.

Methods: The 70 patients who had undergone single-level lumbar discectomy from April 2011 to March 2012 were retrospectively analyzed. Each patient's medical chart and magnetic resonance image were thoroughly reviewed after all the patients had been divided into the drainage and the nondrainage groups. The amounts and durations of the surgical drains in the drainage group were analyzed. Additionally, the levels of C-reactive protein, rates of infection, scores of preoperative and postoperative visual analog scale (VAS), and lengths of hospital stay after operation were compared between the 2 groups.

Results: In this study, 70 patients were retrospectively analyzed; out of which, 42 and 28 patients were included in the drainage and the nondrainage groups, respectively. Two of the postoperative infection cases in the nondrainage group required to undergo repeated operations. The frequency of the postoperative infection cases was higher in the nondrainage group than in the drainage group; however, there was no significant statistical difference between the 2 groups ( $p=0.157)$.

Conclusion: Surgical drains did not elevate postoperative infection. Furthermore, drain tip cultures allowed us to detect postoperative infection at an early stage, and it led to faster initiation of antibiotics treatment.
\end{abstract}

Key Words: Suction $\cdot$ Infection $\cdot$ Hematoma $\cdot$ Discectomy $\cdot$ Lumbar disc disease $\cdot$ Treatment outcome

\section{INTRODUCTION}

The spine surgery can lead to epidural hematoma. The incidence rate of symptomatic epidural hematoma is only $0.1 \%-$ $0.24 \%, 1,9,13)$. Though rare, it can lead to neurological sequelae such as bowel and bladder dysfunction, sexual dysfunction, saddle anesthesia, sciatica, and motor weakness. Closed system surgical drains are performed to prevent these problems. Hematoma is a good culture medium for bacteria; therefore, reducing hematoma is advantageous in reducing infection.

Many surgeons consider that a surgical drain increases the postoperative infection rate re, $^{2,6,18,21)}$. As a foreign body is inserted into a patient, it can lead to local inflammatory responses and can activate host defense system; alternatively, it can act as an inlet of infection. Therefore, there is a controversy about usefulness of surgical drain in single-level lumbar disc surgery and that bleeding is not much.

- Received: November 27, 2015 • Revised: December 31, 2015

- Accepted: January 4, 2016

Corresponding Author: Sang Gu Lee, MD, PhD

Department of Neurosurgery, Gachon University Gil Medical Center,

21 Namdong-daero 774beon-gil, Namdong-gu, Incheon 21565, Korea

Tel: +82-32-460-3304, Fax: +82-32-460-3899

E-mail: samddal@gilhospital.com

$\otimes$ This is an open access article distributed under the terms of the Creative Commons Attribution Non-Commercial License (http://creativecommons.org/licenses/by-nc/4.0/) which permits unrestricted non-commercial use, distribution, and reproduction in any medium, provided the original work is properly cited.
In this study, we retrospectively analyzed the patients who had undergone single-level disc surgeries. The patients were divided into 2 groups: Drainage group and nondrainage group.

\section{MATERIALS AND METHODS}

We studied 70 patients who had undergone single-level lumbar discectomy from April 2011 to March 2012. Three surgeons conducted the surgery in a single center. The patients who had undergone multilevel surgery, fusion surgery, and/or previous lumbar surgery were not included in this study. There were 34 men and 36 women with the mean age of 48.19 years. This study was based on retrospective analysis of the patients' medical records that included their age, sex, diagnosis, level of surgery, mean operation time, length of stay after surgery, past history (hypertension and diabetes), and smoking or not, levels of C-reactive protein (CRP), and scores of visual analogue scale (VAS).

The patients were divided into 2 groups: one that received the surgical drain and the other that did not. There were 42 patients who received the drain that included 21 men and 21 women with mean age of 49.93 years, and there were 28 patients who did not receive the drain that included 13 men and 15 women with mean age of 43.86 years. There was no significant difference between the 2 groups (Table 1$)$.

Both groups received prophylactic antibiotics (1st generation cephalosporin) intravenously for 7 to 8 days. We checked the levels of CRP on postoperative days 1,3 , and 5 . The amounts 
Table 1. Demographics of the groups

\begin{tabular}{|c|c|c|c|c|}
\hline Demographic & Drainage group $(n=42)$ & Nondrainage group $(n=28)$ & Total $(n=70)$ & p-value \\
\hline Sex & & & & 0.811 \\
\hline M:F (ratio) & $21: 21(1)$ & $13: 15(0.87)$ & $34: 36(0.94)$ & \\
\hline Mean age (yr) & 49.93 & 43.86 & 48.19 & 0.225 \\
\hline Mean length of stay (day) & 14.82 & 14.15 & 14.36 & 0.311 \\
\hline Diabetes mellitus, n (\%) & $10(23.81)$ & $2(7.14)$ & $12(17.14)$ & 0.106 \\
\hline Hypertension, n (\%) & $10(23.81)$ & $8(28.57)$ & $18(25.71)$ & 0.781 \\
\hline Smoking, $\mathrm{n}(\%)$ & $4(9.52)$ & $7(25.00)$ & $11(15.71)$ & 0.201 \\
\hline
\end{tabular}

of surgical drainage collected for 24 hours were checked daily at the same time. In drainage group, proximal tip culture of surgical drain was conducted when removed. Between postoperative days 7 and 8 , stitches were removed and the patients were discharged.

We compared the rates of infection, the levels of CRP, and the scores of VAS in preoperative, postoperative, and the first postoperative follow-up phases at the outpatients department. The demographics of the 2 groups were compared using t-test and Fisher exact test. The infection rates of the 2 groups were compared using Fisher exact test. The level of significance was set at $\mathrm{p}=0.05$.

\section{RESULTS}

The mean duration of the surgical drain and the mean of total amounts of drainage were 2.88 days and $71.57 \mathrm{~mL}$, respectively. The daily amounts of drainage on the postoperative days 1,2 , and 3 were $35.4,20.8$, and $14.27 \mathrm{~mL}$, respectively (Fig. 1). All drain tip cultures in drainage group showed no growth. The differences in the levels of CRP between the 2 groups were not significant ( $p>0.05$ ) (Fig. 2). The mean level of CRP in drainage group on postoperative days 1,2 , and 3 were 4.17, 3.76, and $2.41 \mathrm{mg} / \mathrm{L}$ and in nondrainage groups mean level of CRP were 4.89, 5.2, and $3.8 \mathrm{mg} / \mathrm{L}$. The differences in the scores of VAS in preoperative, postoperative, and follow-up phases were not significant between the 2 groups ( $>0.05)$ (Fig. 3). The mean scores of VAS in the drainage group in preoperative, postoperative, and follow-up phase were 7.5, 2.64, and 0.64 and mean scores of VAS in the nondrainage groups were $7.28,2.1$, and 0.76 . The mean length of hospital stay after surgery was 9.68 days; further, it was 8.68 days in the drainage group and 9.87 days in the nondrainage group. There was no significant difference between the 2 groups $(p>0.05)$. The mean operation time was 143.0 minutes. The mean operation time of the drainage group was longer than the nondrainage group (150.2 minutes vs. 130.8 minutes). But there was no significant difference between the 2 groups $(p>0.05)$. In the group that did not receive surgical drain, 2 cases of postoperative wound infection were observed that underwent repeated surgeries. These cases had no history of diabetes or hypertension or smoking. The mean operation

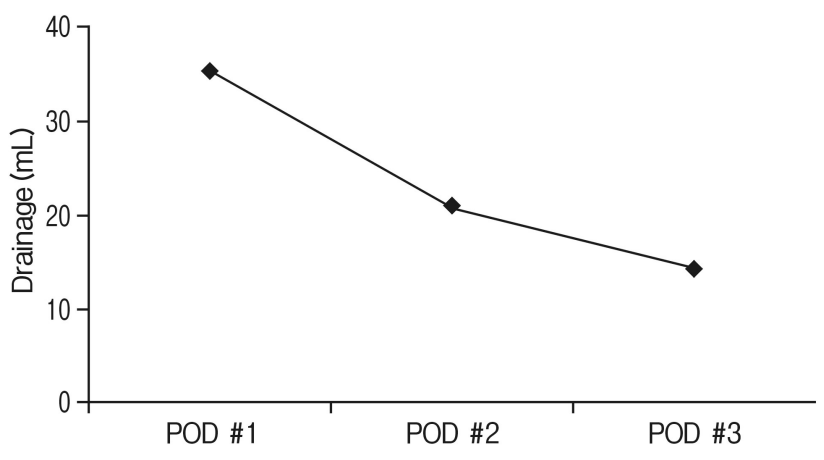

Fig. 1. Amount of surgical drain. POD, postoperative day.

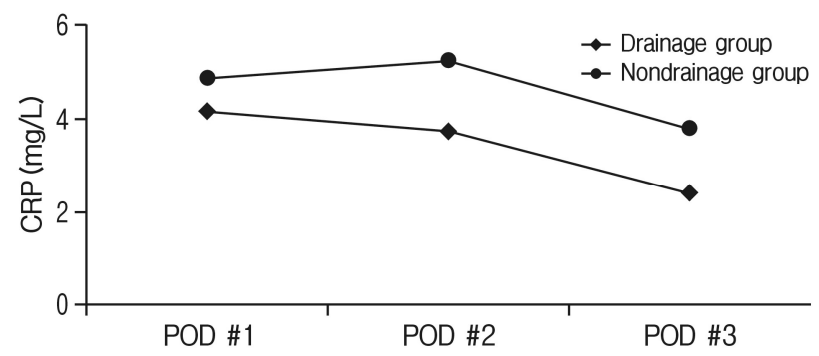

Fig. 2. Level of C-reactive protein (CRP). POD, postoperative day.

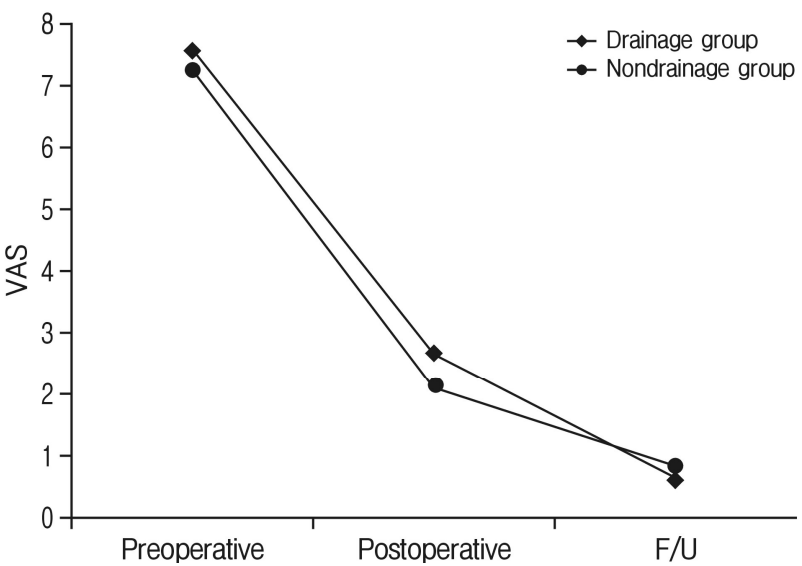

Fig. 3. Visual analogue scale (VAS) in preoperative, postoperative, and follow-up $(\mathrm{F} / \mathrm{U})$ phase. 
Table 2. Frequency of infection in drainage and nondrainage groups

\begin{tabular}{llll}
\hline \hline & No infection & Postoperative infection & Total \\
\hline Surgical drainage & & & p-value \\
Nondrainage group & $26(92.86)$ & $2(7.14)$ & $28(100)$ \\
Drainage group & $42(100)$ & $0(0)$ & $42(100)$ \\
Total & $68(97.14)$ & $2(2.86)$ & $70(100)$ \\
\hline
\end{tabular}

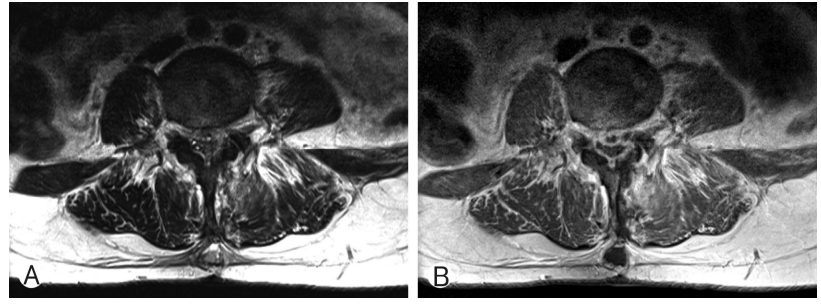

Fig. 4. T2-wighted (A) and gadolinium-enhanced (B) magnetic resonance images demonstrate rim enhancing fluid collection following left sided partial hemi-laminectomy.

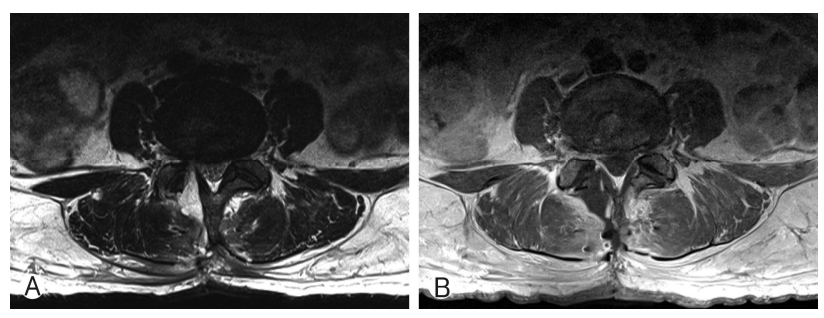

Fig. 5. T2-wighted (A) and gadolinium-enhanced (B) magnetic resonance images demonstrate rim enhancing fluid collection at right sided foraminotomy site, L4-5, with adjacent soft tissue enhancement.

time of infected patients was 100 minutes and that of no infection patients was 144.5 minutes. The operation time of infected patients was shorter than no infection patients, but there was no significance $(p>0.05)$. No postoperative infection case was seen in the group that received surgical drain. There was no statistically significant difference between the 2 groups $(p=0.157)$ (Tables 1,2$)$. The overall infection rate was $2.85 \%$.

One of the 2 infected patients in the group that did not receive surgical drain was a 39-year-old woman who had undergone left L5-S1discectomy. After 13 days of operation, she had fever and pus-like discharge at the operated site. The levels of CRP were elevated to 9.31. She underwent a repeated surgery on postoperative day 14 and received antibiotics treatment for 6 weeks (Fig. 4).

The other patient was a 53-year-old woman who had undergone right L4-L5 discectomy. After 12 days of surgery, discharge from the wound site was observed. The levels of CRP were elevated to 6.76. The lumbar magnetic resonance imaging (MRI) revealed fluid collection with rim enhancement at the operated site and adjacent soft tissue enhancement was also observed. She underwent a repeated surgery on postoperative day 13 and received antibiotics treatment for 6 weeks. The intraoperative pus culture grew methicillin-resistant and coagulase-negative Staphylococcus (Fig. 5).

\section{DISCUSSION}

The incidence of symptomatic epidural hematoma is rare; however, the overall incidence rates of epidural hematomas on the first postoperative day of lumbar decompression surgery were reported using MRI to be as frequent as $86 \%{ }^{12)}$. Postoperative surgical drain cannot only reduce the incidence and severity of hematoma formation but can also reduce the postoperative fibrosis ${ }^{14)}$.

Postoperative infection has been reported after $2 \%-6 \%$ of spinal surgeries. The incidence of postoperative infection can be less than 1\% after decompressive operation and more than $10 \%$ after fusions ${ }^{15)}$. In this study, we analyzed the relation between the surgical drainage and postoperative infection in 70 patients who had undergone single-level lumbar disc surgery. There were 2 cases of postoperative infection and both of them did not receive surgical drains; however, there was no statistical significance. Additionally, there was no significant difference in the outcomes of surgery (pain and length of hospital stay after surgery). This study has some limitations. The small sample size and retrospective nature of the study. There was no increase in infection rate of surgical drain. Additionally, from the financial perspective, there was no significant increase in the length of hospital stay because of surgical drain. The difference in the infection rates of the 2 groups (one that received the surgical drains and the other that did not) was not statistically significant.

Although many surgeons consider that surgical drain insertions increase infection rate, many studies have also shown no increase in the infection rate of surgical drains ${ }^{3,4,8,16}$. Kanayama et al. ${ }^{8)}$ studied drain use after single-level lumbar decompression surgery and found "wound infection was not influenced by use of a drain." More recently, Poorman et al. ${ }^{17)}$ studied drain use in cervical surgery and concluded "no differences in incidence of complications." Ho et al. ${ }^{7}$ reported significant increase the incidence of delayed postoperative infection in patients who did not received surgical drains.

Though it may not always be correct, the tip cultures of surgical drains can allow us to detect postoperative infection at an early stage, and it can lead to faster initiation of antibiotics treatment ${ }^{10,11,19,20)}$. Sankar et al. ${ }^{19)}$ studied 214 patients 
who received orthopedic operation. There was significant relationship between positive tip culture and wound infection. Positive tip culture predicts wound infection in 50\% and a negative culture virtually excludes the possibility of a deep infection. Kobayashi et al. ${ }^{11)}$ studied the efficacy of use of drain tip culture and conclude "drain tip culture is useful for early detection of surgical site infection caused by methicillin resistant bacteria." In their series, there were 34 cases of positive tip culture and there were 19 surgical site infections. Drain tip culture had a sensitivity of 52\%, specificity of $92 \%$ and the association between positive tip culture and wound infection was significant $(p<0.05)$. In our study, the patients who underwent postoperative infection may have an opportunity to detect it earlier if they received drain tip culture.

Surgical drains can reduce the risk of hematoma formation and can detect postoperative infection early by conducting drain tip culture. However, even though simple, inserting surgical drain require additional effort of medical worker, time, cost of material, postoperative care and patient's discomfort. The decision to use or not a surgical drain is left to the surgeon's discretion but using surgical drain can be considered in patient who has bleeding tendency and who has susceptibility to infection. More studies need to be conducted about this subject of surgical drain.

\section{CONCLUSION}

Although many surgeons are apprehensive about postoperative infection by surgical drainage, no increase in infection rate and no difference in wound healing or postoperative neurological deficit have been observed. Conversely, surgical drains have a positive influence on reducing infection by reducing hematoma. The tip cultures of surgical drains can be an effective means of detection of the postoperative infection. It can be useful to use surgical drain in some cases.

\section{CONFLICT OF INTEREST}

No potential conflict of interest relevant to this article was reported.

\section{REFERENCES}

1. Awad JN, Kebaish KM, Donigan J, Cohen DB, Kostuik JP: Analysis of the risk factors for the development of post-operative spinal epidural haematoma. J Bone Joint Surg Br 87:12481252, 2005

2. Bachoura A, Guitton TG, Smith RM, Vrahas MS, Zurakowski D, Ring D: Infirmity and injury complexity are risk factors for surgical-site infection after operative fracture care. Clin Orthop Relat Res 469:2621-2630, 2011

3. Brown MD, Brookfield KF: A randomized study of closed wound suction drainage for extensive lumbar spine surgery. Spine (Phila $\mathrm{Pa}$ 1976) 29:1066-1068, 2004
4. Chen S, Anderson MV, Cheng WK, Wongworawat MD: Diabetes associated with increased surgical site infections in spinal arthrodesis. Clin Orthop Relat Res 467:1670-1673, 2009

5. Derksen WJ, Verhoeven BA, van de Mortel RH, Moll FL, de Vries JP: Risk factors for surgical-site infection following common femoral artery endarterectomy. Vasc Endovascular Surg 43:69-75, 2009

6. Fatica CA, Gordon SM, Zins JE: The role of preoperative antibiotic prophylaxis in cosmetic surgery. Plast Reconstr Surg 109: 2570-2073, 2002

7. Ho C, Sucato DJ, Richards BS: Risk factors for the development of delayed infections following posterior spinal fusion and instrumentation in adolescent idiopathic scoliosis patients. Spine (Phila Pa 1976) 32:2272-2277, 2007

8. Kanayama M, Oha F, Togawa D, Shigenobu K, Hashimoto T: Is closed-suction drainage necessary for single-level lumbar decompression?: review of 560 cases. Clin Orthop Relat Res 468: 2690-2694, 2010

9. Kebaish KM, Awad JN: Spinal epidural hematoma causing acute cauda equina syndrome. Neurosurg Focus 16:e1, 2004

10. Kim T, Han JH, Kim HB, Song KH, Kim ES, Kim YH, et al: Risk factors of surgical site infections after supratentorial elective surgery: a focus on the efficacy of the wound-drain-tip culture. Acta Neurochir (Wien) 155:2165-2170, 2013

11. Kobayashi K, Imagama S, Ito Z, Ando K, Yagi H, Hida T, et al: Is a drain tip culture required after spinal surgery? J Spinal Disord Tech [Epub ahead of print], 2015

12. Kotilainen E, Alanen A, Erkintalo M, Helenius H, Valtonen S: Postoperative hematomas after successful lumbar microdiscectomy or percutaneous nucleotomy: a magnetic resonance imaging study. Surg Neurol 41:98-105, 1994

13. Kou J, Fischgrund J, Biddinger A, Herkowitz H: Risk factors for spinal epidural hematoma after spinal surgery. Spine (Phila Pa 1976) 27:1670-1673, 2002

14. Mirzai H, Eminoglu M, Orguc S: Are drains useful for lumbar disc surgery? A prospective, randomized clinical study. J Spinal Disord Tech 19:171-177, 2006

15. O'Toole JE, Eichholz KM, Fessler RG: Surgical site infection rates after minimally invasive spinal surgery. J Neurosurg Spine 11:471-476, 2009

16. Payne DH, Fischgrund JS, Herkowitz HN, Barry RL, Kurz LT, Montgomery DM: Efficacy of closed wound suction drainage after single-level lumbar laminectomy. J Spinal Disord 9:401-403, 1996

17. Poorman CE, Passias PG, Bianco KM, Boniello A, Yang S, Gerling MC: Effectiveness of postoperative wound drains in oneand two-level cervical spine fusions. Int J Spine Surg 8:34, 2014

18. Sangrasi AK, Leghari AA, Memon A, Talpur AK, Qureshi GA, Memon JM: Surgical site infection rate and associated risk factors in elective general surgery at a public sector medical university in Pakistan. Int Wound J 5:74-78, 2008

19. Sankar B, Ray P, Rai J: Suction drain tip culture in orthopaedic surgery: a prospective study of 214 clean operations. Int Orthop 28:311-314, 2004

20. Sørensen AI, Sørensen TS: Bacterial growth on suction drain tips. Prospective study of 489 clean orthopedic operations. Acta Orthop Scand 62:451-454, 1991

21. Tabaqchali MA, Hanson JM, Proud G: Drains for thyroidectomy/parathyroidectomy: fact or fiction? Ann R Coll Surg Engl 81:302-305, 1999 